\title{
Mercury Underpotential Deposition to Determine Iridium and Iridium Oxide Electrochemical Surface Areas
}

\author{
Shaun M. Alia, ${ }^{\mathrm{z}}$ Katherine E. Hurst, Shyam S. Kocha, ${ }^{*}$ and Bryan S. Pivovar* \\ Chemical and Materials Science Center, National Renewable Energy Laboratory, Golden, Colorado 80401, USA
}

\begin{abstract}
Determining the surface areas of electrocatalysts is critical for separating the key properties of area-specific activity and electrochemical surface area from mass activity. Hydrogen underpotential deposition and carbon monoxide oxidation are typically used to evaluate iridium (Ir) surface areas, but are ineffective on oxides and can be sensitive to surface oxides formed on Ir metals. Mercury underpotential deposition is presented in this study as an alternative, able to produce reasonable surface areas on Ir and Ir oxide nanoparticles, and able to produce similar surface areas prior to and following characterization in oxygen evolution. Reliable electrochemical surface areas allow for comparative studies of different catalyst types and the characterization of advanced oxygen evolution catalysts. They also enable the study of catalyst degradation in durability testing, both areas of increasing importance within electrolysis and electrocatalysis.

(C) The Author(s) 2016. Published by ECS. This is an open access article distributed under the terms of the Creative Commons Attribution Non-Commercial No Derivatives 4.0 License (CC BY-NC-ND, http://creativecommons.org/licenses/by-nc-nd/4.0/), which permits non-commercial reuse, distribution, and reproduction in any medium, provided the original work is not changed in any way and is properly cited. For permission for commercial reuse, please email: oa@electrochem.org. [DOI: 10.1149/2.0071611jes] All rights reserved.
\end{abstract}

Manuscript submitted April 7, 2016; revised manuscript received May 9, 2016. Published June 2, 2016. This paper is part of the JES

Focus Issue on Electrolysis for Increased Renewable Energy Penetration.

Within the United States, hydrogen is a significant chemical commodity primarily produced by steam methane reformation. ${ }^{1} \mathrm{Al}-$ though a relatively small fraction of hydrogen production comes from the electrochemical splitting of water today, it is a commercial technology in limited application space that will continue to grow as costs decrease. Additionally, the process is expected to have a larger role in the future as the costs decrease and deployment variable renewable sources of energy increase. ${ }^{2,3}$ Within acidic electrolyzers, work often focuses on the activity and durability of anode catalysts in the oxygen evolution reaction (OER) due to the slower kinetics (relative to hydrogen evolution, HER) and the high operating potential. ${ }^{4,5}$ Iridium (Ir) is typically used in acidic electrolyzers for OER due to reasonable activity and stability. ${ }^{6-12} \mathrm{Al}$ though platinum $(\mathrm{Pt})$ and ruthenium $(\mathrm{Ru})$ are commonly investigated as alternatives, Pt generally requires a higher overpotential while $\mathrm{Ru}$ has dissolution or durability concerns at typical operating potentials. ${ }^{9,13-16}$

The determination of Ir electrochemical surface areas (ECAs) allows for the number of Ir sites electrochemically available to be quantified, as well as the specific activity or quality of those sites in OER. Determining ECAs is of interest in catalyst development, to compare different catalyst types including the development of advanced OER electrocatalysts. Ir ECAs are also of interest in evaluating durability as activity changes can be quantified in terms of deteriorating or increasing site quantity or quality. ${ }^{17}$ Ir ECAs have been determined previously, primarily by hydrogen underpotential deposition, carbon monoxide stripping, and capacitance, but have typically been limited to specific catalyst types (hydrogen and carbon monoxide for Ir metal, capacitance for Ir oxide) and pre-durability measurements. ${ }^{9,18-20}$ The underpotential deposition of metals, including mercury onto Ir films, and lead, copper, cadmium, and zinc onto Ir oxide films has been reported previously. ${ }^{21-26}$ No method is widely used, however, to determine the ECAs of both Ir metals and oxides, prior to and following OER characterization.

This study presents mercury underpotential deposition as a method to determine the ECAs of polycrystalline Ir, Ir nanoparticles, and Ir oxide nanoparticles in rotating disk electrode (RDE) half-cells. These types of studies are critical for baselining catalyst performance and developing evaluation protocols for OER electrocatalysis.

\footnotetext{
*Electrochemical Society Member.
}

${ }^{\mathrm{z}}$ E-mail: shaun.alia@nrel.gov

\section{Experimental}

Polycrystalline Ir (American Elements, product number IR-M03M-D.4MMT, $\geq 99.9 \%$ Ir), Ir nanoparticles (Ir black, Johnson Matthey, product number C2026/160000, $\geq 93.0 \mathrm{wt} \%$ Ir), and Ir oxide nanoparticles (Alfa Aesar, product number 43396, $\geq 84.5 \%$ Ir) were examined. Ir inks consisted of $3.5 \mathrm{mg}$ of Ir catalyst, suspended in 7.6 $\mathrm{ml}$ of water, $2.4 \mathrm{ml}$ of isopropanol, and $40 \mu \mathrm{l}$ of Nafion ionomer (5 wt $\%$, Sigma Aldrich). The inks were put into an ice bath and bath sonicated for $20 \mathrm{~min}$. After sonication, $10 \mu \mathrm{l}$ of the inks were pipetted onto glassy carbon or polycrystalline gold $(\mathrm{Au})$ electrodes and dried in air at $40^{\circ} \mathrm{C}$ for $20 \mathrm{~min}$. Catalyst loadings from this coating process were $17.8 \mu \mathrm{g}_{\text {Ir }} \mathrm{cm}_{\text {elec }}{ }^{-2}$.

Electrochemical measurements were taken in a RDE half-cell equipped with a working electrode (polycrystalline $\mathrm{Au}$ or glassy carbon), Au mesh counter electrode, and reversible hydrogen reference electrode (RHE), connected to the main cell through a Luggin capillary. ${ }^{27}$ Rotating of the working electrode was controlled by a modulated speed rotator (Pine Instruments) and electrochemical measurements were taken with an Autolab PGSTAT302N potentiostat (Eco Chemie, Metrohm Autolab B.V.).

ECA measurements by mercury underpotential deposition were taken in a $0.1 \mathrm{M}$ perchloric acid electrolyte containing $1 \mathrm{mM}$ mercury (II) nitrate (Sigma Aldrich), at variable potential ranges and scan rates, and assumed a Coulombic charge of $138.6 \mu \mathrm{C} \mathrm{cm}_{\text {Ir }}{ }^{-2}$ (42\% efficiency of $\left.330 \mu \mathrm{C} \mathrm{cm}_{\mathrm{Ir}}{ }^{-2}\right) .{ }^{22}$ ECA measurements by hydrogen underpotential deposition were taken in a $0.1 \mathrm{M}$ perchloric acid electrolyte in the potential range $0.025-0.55 \mathrm{~V}$ vs. RHE and assumed a Coulombic charge of $179 \mu \mathrm{C} \mathrm{cm}_{\mathrm{Ir}}{ }^{-2} \cdot{ }^{18}$ ECA measurements by carbon monoxide stripping assumed a Coulombic charge of $358 \mu \mathrm{C} \mathrm{cm}_{\text {Ir }}{ }^{-2}$, and were completed by holding a potential of $0.2 \mathrm{~V}$ for $20 \mathrm{~min}$, the first 10 min with a carbon monoxide purge and the second 10 min with a nitrogen purge. ${ }^{9,18}$ Following the 20 min hold, the potential was swept anodically at $20 \mathrm{mV} \mathrm{s}^{-1}$ to oxidize the adsorbed carbon monoxide. Throughout the available literature, a range of values are reported for the Coulombic charge conversion for hydrogen underpotential deposition and carbon monoxide oxidation on Ir. Since these processes can be sensitive to the formation of surface Ir oxides, electrode history and exposure to elevated potential can impact ECA calculations in a meaningful way. The above Coulombic charge values were used in this study since they gave a reasonable roughness factor on polycrystalline Ir. The ECA values produced by these methods, however, may be impacted by the choice in conversion factor. 

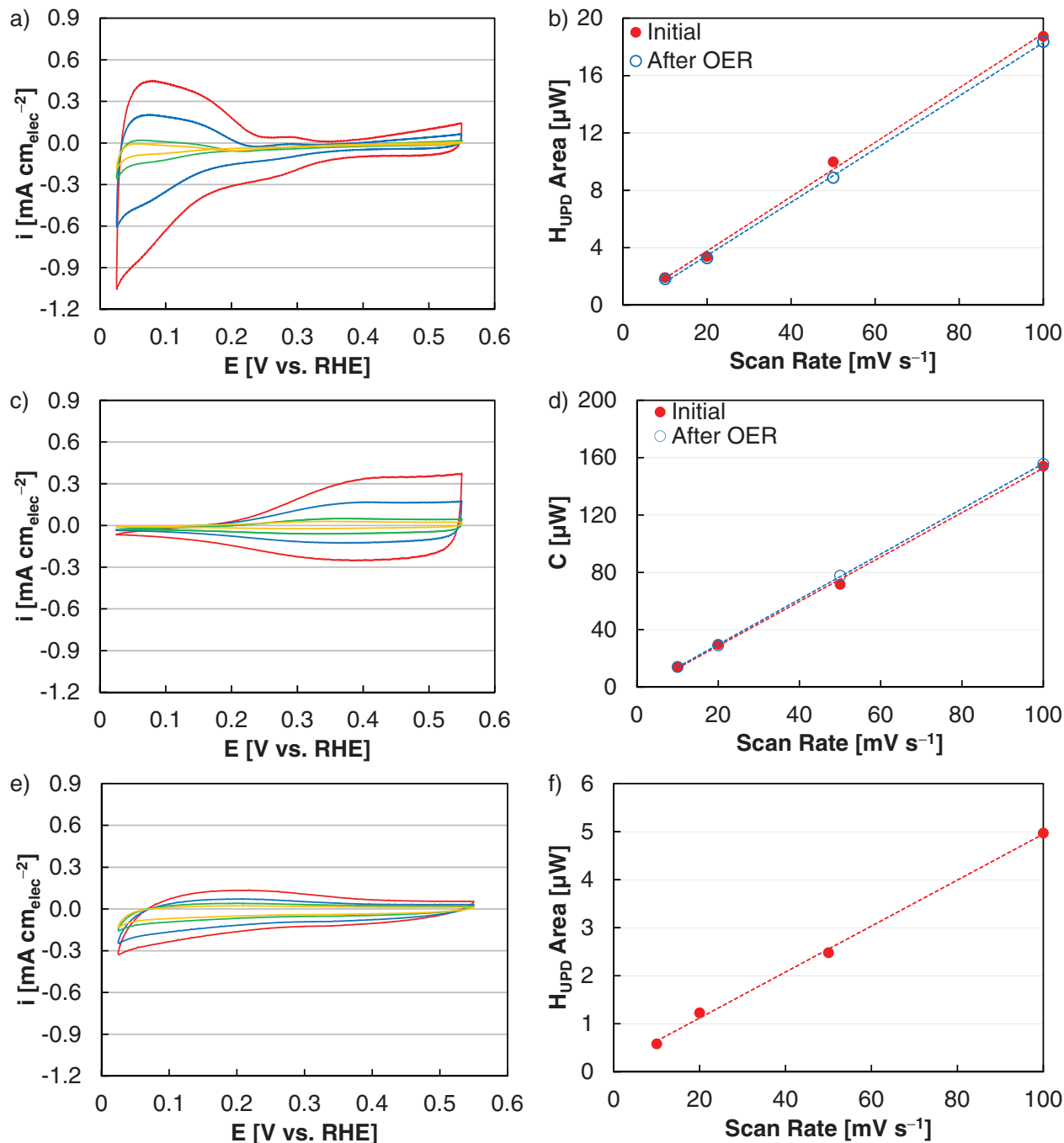

Figure 1. Cyclic voltammograms of (a) Ir nanoparticles, (c) Ir oxide nanoparticles, and (e) polycrystalline Ir in a $0.1 \mathrm{M}$ perchloric acid electrolyte at 100 (red), 50 (blue), 20 (green), and $10 \mathrm{mV} \mathrm{s}^{-1}$ (yellow). Charges associated with hydrogen adsorption on (b) Ir nanoparticles and (f) polycrystalline Ir, prior to (red) and following (blue) electrochemical break-in for OER. (d) The capacitance of Ir oxide nanoparticles based on scan rate in the potential range $0.025-1.4 \mathrm{~V}$ vs. RHE prior to (red) and following (blue) electrochemical break-in for OER.

Electrochemical conditioning for OER was completed by potential cycling 10 times in the potential range $1.2-1.8 \mathrm{~V}$ vs. RHE at $100 \mathrm{mV}$ $\mathrm{s}^{-1}$ and $2500 \mathrm{rpm}$. ECA measurements were completed prior to and following electrochemical conditioning to evaluate method viability following OER testing and durability.

The ECA measurements vary with electrode loading and Nafion content. ${ }^{28}$ Ir and Ir oxide ECAs decreased at higher catalyst loadings, likely since lower loadings produced a thinner film and improved Ir utilization. At lower Nafion content, or in inks without Nafion, the ECA decreased, likely since the ink formed a visibly poorer dispersion. At higher Nafion content, the ECAs were not significantly impacted, although the amount of Nafion used in this study $(<0.0098 \mathrm{wt} \%$ of the electrode loading, $0.039 \mathrm{wt} \%$ was the highest examined) was potentially too low to observe an effect.

Brunauer-Emmett-Teller (BET) measurements were taken with a Micromeritics Autosorb 2020. Prior to measurement, each sample was heated for $1 \mathrm{~h}$ at $120^{\circ} \mathrm{C}$ to desorb any adsorbed water at ambient conditions. BET measurements were taken on Ir and Ir oxide nanoparticles without any Nafion ionomer added.

\section{Results}

The examined Ir nanoparticles (Ir black) were from Johnson Matthey, product number C2026/160000. The manufacturer-specified surface area was $25-40 \mathrm{~m}^{2} \mathrm{~g}^{-1}$ with an Ir content of $\geq 93.0 \mathrm{wt} \%$. The examined Ir oxide nanoparticles (Ir (IV) oxide) were from Alfa Aesar, product number 43396 . No manufacturer-specified surface area was available, and the Ir content was $\geq 84.5 \mathrm{wt} \%$. The examined polycrystalline Ir disk was from American Elements, product number IR-M-03M-D.4MMT and was $\geq 99.9 \%$ Ir.

Hydrogen underpotential deposition.-Cyclic voltammograms were completed in the potential region for the adsorption and desorption of a monolayer of hydrogen. ${ }^{18,19,29}$ Assuming a Coulombic charge of $179 \mu \mathrm{C} \mathrm{cm}_{\mathrm{Ir}}{ }^{-2}$, experiments on a polished, polycrystalline Ir disk gave a roughness factor of 1.4 , supporting that $179 \mu \mathrm{C} \mathrm{cm}_{\mathrm{Ir}}{ }^{-2}$ was a reasonable value for calculating ECA from the measured charge (Figure 1). ${ }^{18}$ On Ir nanoparticles, the ECA was comparable to the BET value $\left(28.7 \mathrm{~m}^{2} \mathrm{~g}_{\mathrm{Ir}}^{-1}\right.$ electrochemically, $34 \mathrm{~m}^{2} \mathrm{~g}_{\mathrm{Ir}}{ }^{-1}$ BET). ECA values were also consistent for a variety of scan rates, and only slightly dropped (to $27.1 \mathrm{~m}^{2} \mathrm{~g}_{\mathrm{Ir}}{ }^{-1}$ ) following characterization for OER. For Ir oxide, however, no response for hydrogen adsorption and desorption was found. Alternatively, Ir oxide surface areas can be evaluated by their capacitance in the potential range between HER and OER (0.025-1.4 V vs. RHE) ${ }^{30-32}$ In most electrolysis studies, however, capacitance comparisons are made on a qualitative basis to optimize catalyst and electrolyzer performance, and are not normalized to a 

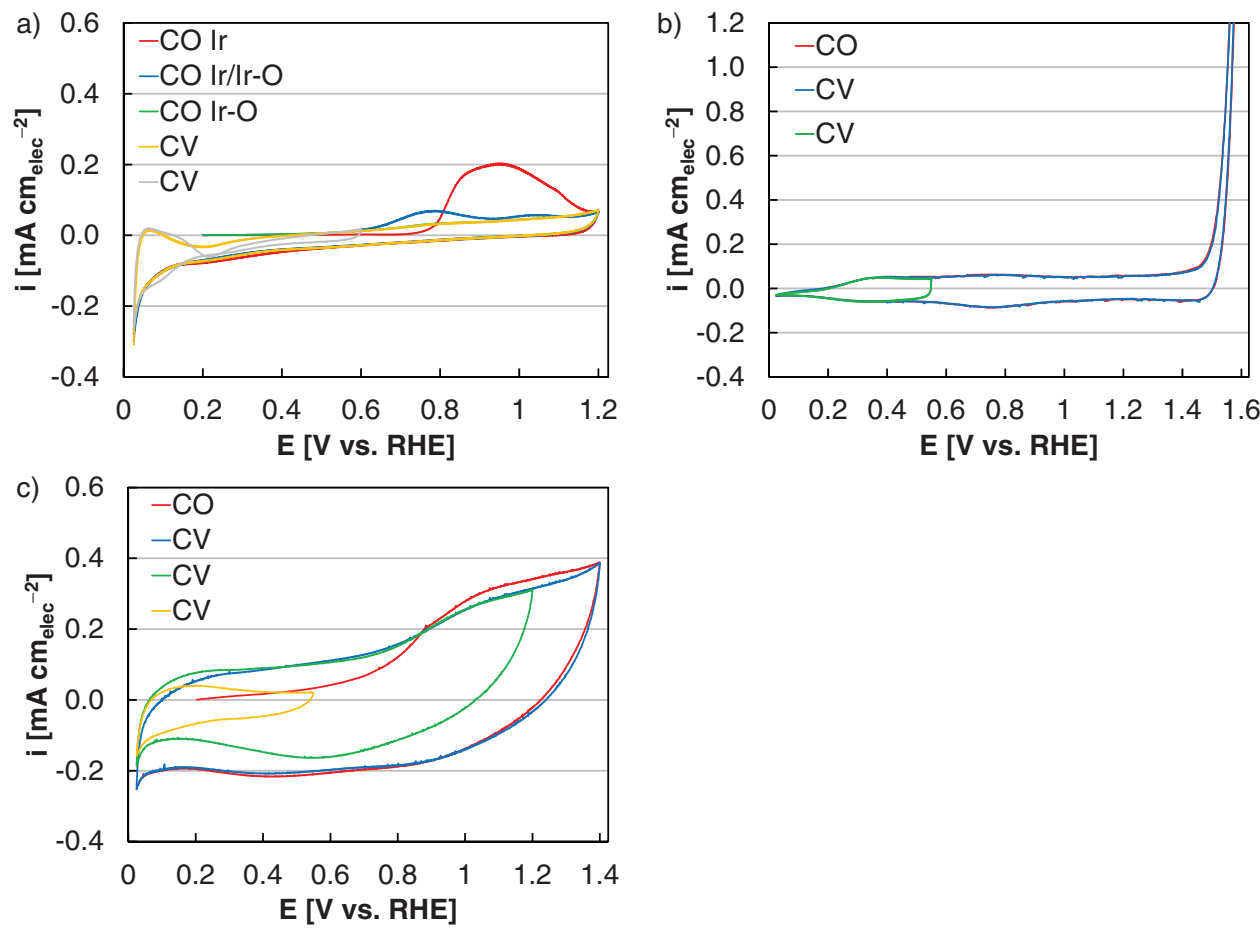

Figure 2. Carbon monoxide oxidation voltammograms and accompanying cyclic voltammograms on (a) Ir nanoparticles (first carbon monoxide oxidation experiment, red; second carbon monoxide oxidation experiment, blue; carbon monoxide oxidation after OER electrochemical conditioning, green), (b) Ir oxide nanoparticles, and (c) polycrystalline Ir. Experiments were completed in $0.1 \mathrm{M}$ perchloric acid at a scan rate of $20 \mathrm{mV} \mathrm{s}^{-1}$.

Coulombic charge. ${ }^{6,10,30,33}$ Reported Coulombic charges for the capacitance of Ir oxide can further vary between 1 and several hundred $\mathrm{mC} \mathrm{cm}_{\mathrm{Ir}}{ }^{-2}$ based on the experiment type (faradaic or capacitive), medium, and deposition technique. ${ }^{34-38}$ The mass-based capacitances found in this study on Ir oxide are comparable to those previously found in RDE half-cells and single-cell electrolyzers. ${ }^{6,30}$ Capacitance has also been used to determine the ECA of Ir nanoparticles and baseline its activity in OER. ${ }^{39}$ Although an ECA on Ir can be determined by capacitance, the conversion factor between metals and oxides would need to vary greatly (Figure 1). This would not allow for the comparison of different catalyst types in cases where the oxide content or degree of oxide formation was not known. It would also not allow for durability studies, since the degree of oxide or oxide growth could not be decoupled from the ECA measurement.

While hydrogen underpotential deposition can be used to calculate the ECA of Ir metals, it cannot be used to calculate the ECA of oxides. There are also concerns that hydrogen adsorption may be sensitive to surface oxidation in smaller nanoparticles. ${ }^{9}$ The method may also be ineffective with mixed metals/oxides and for measurements following durability testing at elevated potential, where the oxide layer thickness can increase.

Carbon monoxide.-Carbon monoxide oxidation has been used to determine the ECAs of a variety of metals in RDE half-cell testing. ${ }^{20,40-43}$ On polycrystalline Ir, integration of the carbon monoxide oxidation peak produced a surface roughness of 1.6, assuming a Coulombic charge response of $358 \mu \mathrm{C} \mathrm{cm}_{\mathrm{Ir}}{ }^{-2}$ (Figure 2) ${ }^{9,18}$ Increasing the upper bound potential, however, did distort the cyclic voltammogram. The large positive charge response during anodic sweeps were likely due to surface Ir oxidation; subsequent cathodic scans produced a large plateau likely due to surface reduction, blurring the double charging layer and hydrogen adsorption region. The oxidation of an adsorbed carbon monoxide layer on Ir nanoparticles yielded an ECA of $30.8 \mathrm{~m}^{2} \mathrm{~g}_{\mathrm{Ir}}{ }^{-1}$, comparable to the ECA from hydrogen underpotential deposition. This value, however, was only attainable if the catalyst never saw potentials above $0.6 \mathrm{~V}$. Following one sweep to
$1.2 \mathrm{~V}$, the next carbon monoxide oxidation experiment produced an ECA of $6.6 \mathrm{~m}^{2} \mathrm{~g}_{\mathrm{Ir}}{ }^{-1}$, and after OER characterization, no carbon monoxide could be adsorbed. Carbon monoxide could also not be adsorbed onto the Ir oxide nanoparticles. Although carbon monoxide can produce reasonable ECAs when performed on Ir metals, it was ineffective on oxides or once substantial surface oxides were formed.

Mercury underpotential deposition.-Mercury underpotential deposition was previously completed on polycrystalline $\mathrm{Ir}$ and found to produce a Coulombic charge of $138.6 \mu \mathrm{C} \mathrm{cm}_{\mathrm{Ir}}{ }^{-2}$ for the desorption of an adsorbed monolayer. ${ }^{22}$ In this study, experiments on polycrystalline Ir using $138.6 \mu \mathrm{C} \mathrm{cm}_{\mathrm{Ir}}{ }^{-2}$ as a conversion factor produced a roughness factor of 1.3, consistent with hydrogen underpotential deposition and carbon monoxide stripping (Figure 3d). Ir nanoparticle ECAs were also reasonable compared to those determined during BET measurements and the aforementioned electrochemical approaches (Figure 3a). Cyclic voltammograms of mercury-Ir contained several features (Figure $3 b){ }^{22} \mathrm{~A}$ monolayer of mercury adsorbed onto $\mathrm{Ir}$ in the cathodic peak at $0.25 \mathrm{~V}$. At potentials lower than $0.25 \mathrm{~V}$, bulk mercury reduction (cathodic) occurred. During the anodic scan, bulk mercury oxidation occurred at potentials greater than $-0.2 \mathrm{~V}$, depending on the lower bound potential, and the mercury monolayer desorbed in the anodic peak at $0.35 \mathrm{~V}$. If significant amounts of mercury deposited onto Ir by scanning to lower potentials, those layers oxidized over a wide range of potentials during the anodic scan and in some cases caused distortion. Mercury adsorption and desorption also occurred on Ir oxide nanoparticles, producing ECAs comparable to BET values (Figure 3c).

Ir and Ir oxide ECAs were calculated by integrating the charge of the anodic peak for the desorption of a mercury monolayer (Figure 4). Cyclic voltammograms, in the absence of mercury nitrate, were used as background subtraction to remove charges due to capacitance or the double charging layer. For both Ir and Ir oxide nanoparticles, similar ECAs were obtained at various scan rates, as well as before and after OER characterization. Cathodic peaks could similarly be used in the calculation of ECA values; a slight tilt in the voltammograms 

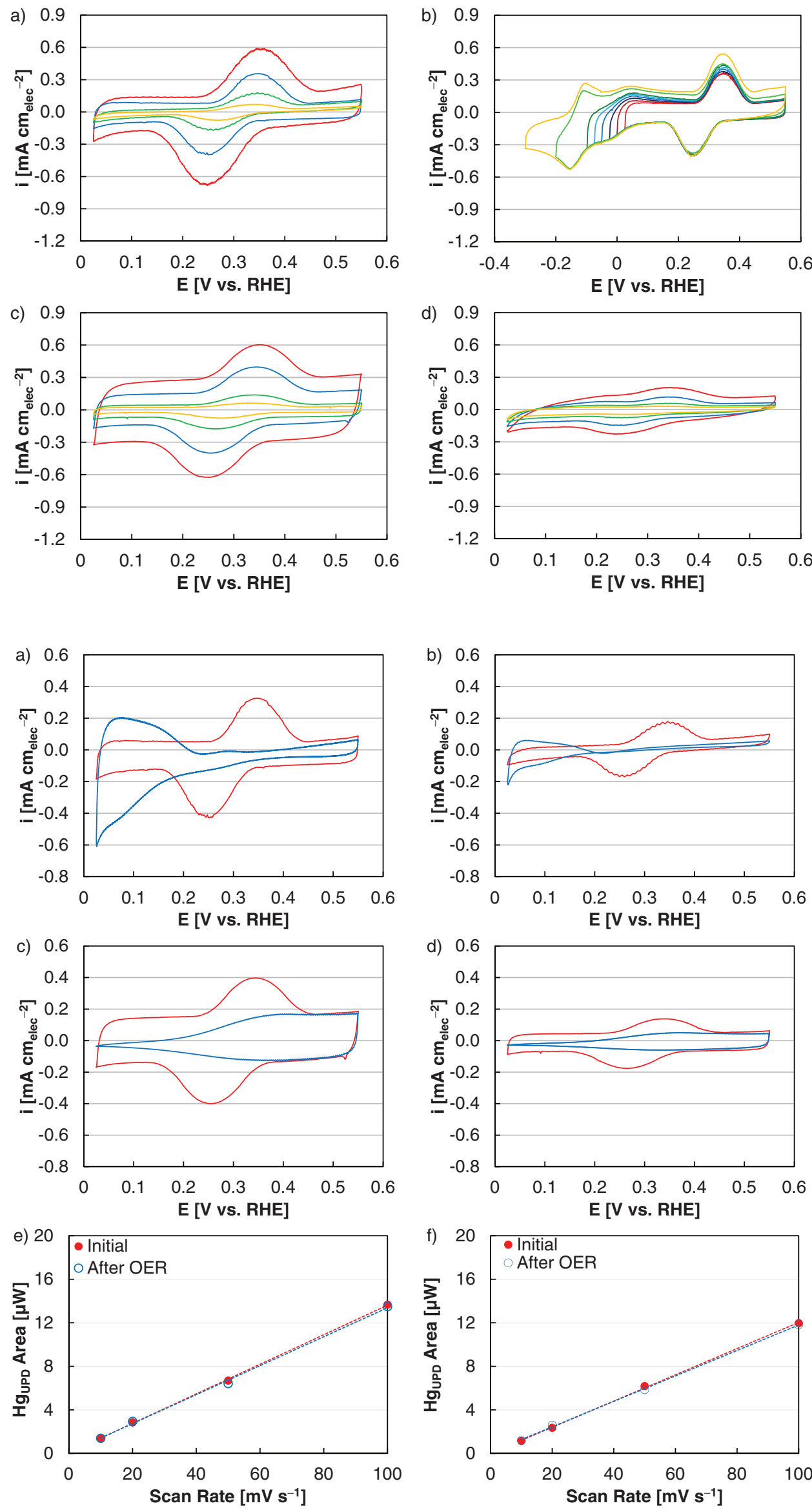
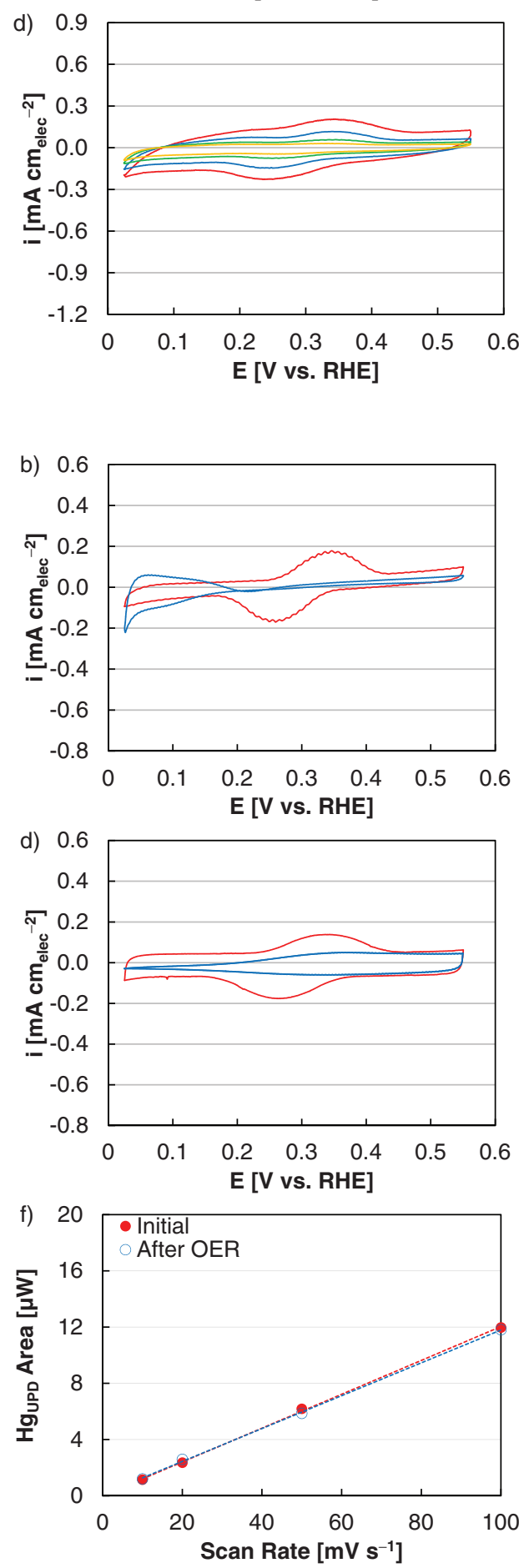

Figure 3. Cyclic voltammograms of (a-b) Ir nanoparticles, (c) Ir oxide nanoparticles, and (d) polycrystalline Ir in $0.1 \mathrm{M}$ perchloric acid containing $1 \mathrm{mM}$ mercury nitrate. Voltammograms in (a), (b), and (d) were in the potential range $0.025-0.55 \mathrm{~V}$ and at 100 (red), 50 (blue), 20 (green), and 10 (yellow) $\mathrm{mV} \mathrm{s}^{-1}$. Voltammograms in (b) were at a variable potential range and at $50 \mathrm{mV} \mathrm{s}^{-1}$.

Figure 4. Cyclic voltammograms of Ir nanoparticles, (a) 50 and (b) $20 \mathrm{mV} \mathrm{s}^{-1}$, and of Ir oxide nanoparticles, (c) 50 and (d) 20 $\mathrm{mV} \mathrm{s}^{-1}$, in a $0.1 \mathrm{M}$ perchloric acid electrolyte (blue) and a $0.1 \mathrm{M}$ perchloric acid electrolyte containing $1 \mathrm{~mm}$ mercury nitrate (red). Charges associated with mercury adsorption on (e) Ir nanoparticles and (f) Ir oxide nanoparticles prior to (red) and following (blue) electrochemical break-in for OER. 

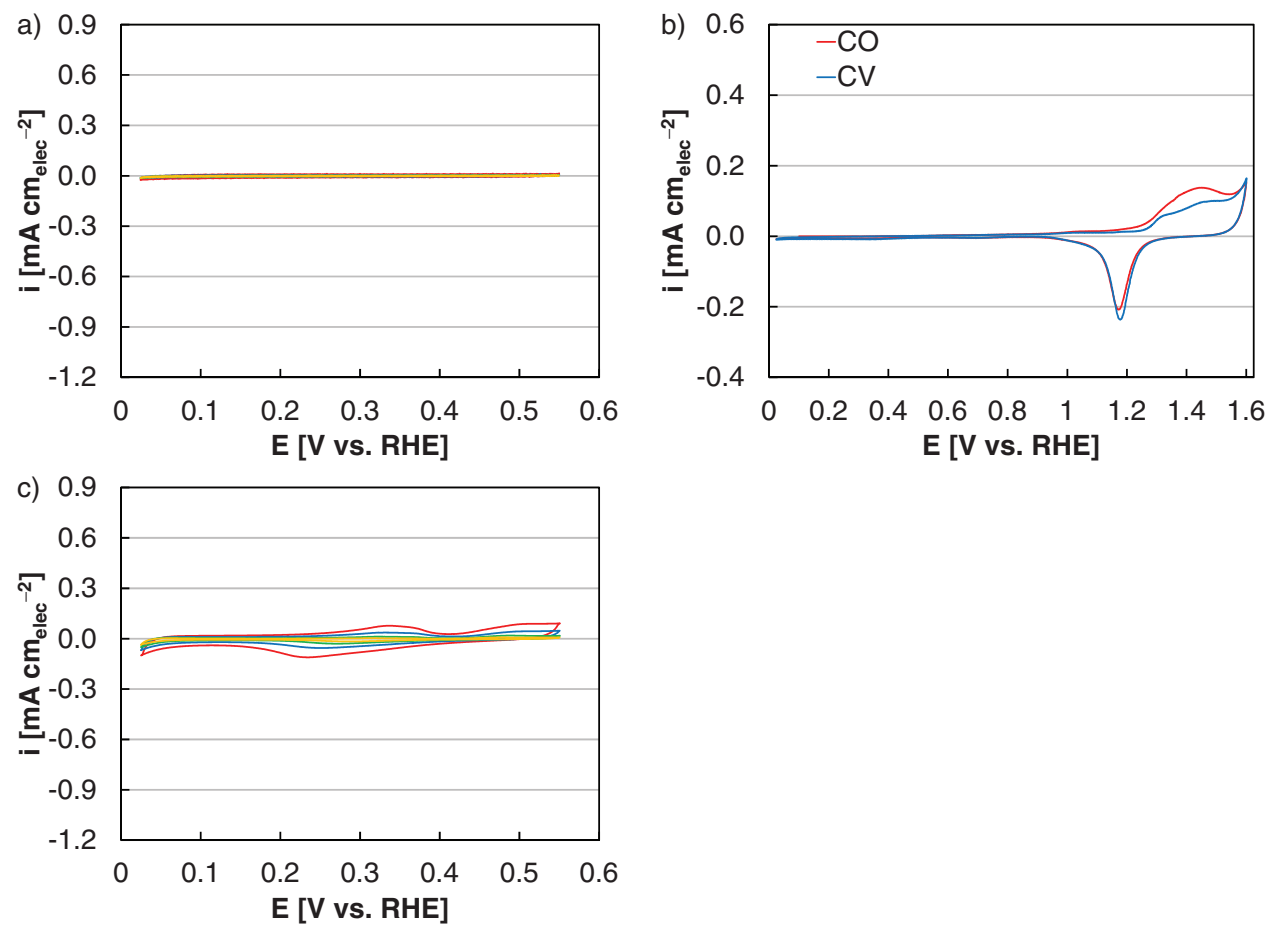

Figure 5. Voltammograms of polycrystalline Au in (a) hydrogen underpotential deposition, (b) carbon monoxide oxidation, and (c) mercury underpotential deposition experiments. (a) Hydrogen underpotential deposition experiments were completed by cyclic voltammograms in $0.1 \mathrm{M}$ perchloric acid at 100 (red), 50 (blue), 20 (green), and 10 (yellow) $\mathrm{mV} \mathrm{s}^{-1}$. (b) Carbon monoxide oxidation voltammograms and accompanying cyclic voltammograms in $0.1 \mathrm{M}$ perchloric acid at a scan rate of $20 \mathrm{mV} \mathrm{s}^{-1}$. (c) Cyclic voltammograms in $0.1 \mathrm{M}$ perchloric acid containing $1 \mathrm{~mm}$ mercury nitrate at 100 (red), 50 (blue), 20 (green), and 10 (yellow) $\mathrm{mV} \mathrm{s}^{-1}$.

at slower scan rates, however, may make the integration bounds less clear graphically. Significant advantages of the mercury underpotential deposition method include the ability to measure ECAs on Ir and Ir oxide, and the method's apparent insensitivity to OER characterization at high potentials.

The electrochemical characterization of Ir catalysts for OER requires elevated potentials in RDE half-cells, typically to 1.8 or $2.0 \mathrm{~V}$. Durability testing of the materials, whether by potential hold or cycling, requires exposure to elevated potentials over significant periods of time. Working electrodes for OER characterization in RDE halfcells, therefore, typically consist of polycrystalline $\mathrm{Au}$ as opposed to glassy carbon. ${ }^{16}$ A polycrystalline Au electrode was examined and found to have no participation in hydrogen adsorption and desorption (Figure 5a). Polycrystalline Au oxidized carbon monoxide, but the potential at which the reaction occurred was much higher than on Ir metal (Figure 5b). ${ }^{42}$ In mercury underpotential deposition, however, Au did adsorb and desorb mercury in a similar potential range to Ir (Figure $5 \mathrm{c}) .{ }^{44}$ Compared to moderately high surface area Ir catalysts, the charges from polycrystalline Au were small and could be subtracted as background; at smaller surface areas and catalyst loadings, however, the contribution from the polycrystalline $\mathrm{Au}$ substrate may produce a meaningful interference. For the Ir and Ir oxide nanoparticles characterized in this study, similar ECAs were produced with glassy carbon and polycrystalline Au substrates if the Au-based data was background subtracted for the Au contribution.

On polycrystalline Ir, hydrogen underpotential deposition, carbon monoxide oxidation, and mercury underpotential deposition gave roughness factors of $1.4,1.6$, and 1.3. These roughness factors are typical and within reasonable values, but do vary based on the evaluation method. The ECA values produced by these methods may be impacted by the choice in conversion factor. Ir and Ir oxide nanoparticle catalysts were also evaluated by BET, which appeared to give comparable values to those measured electrochemically (Table I). The observed ECAs were close to but lower than the BET values, expected since the ECA measurement depends on coating quality and catalyst loading.
Hydrogen underpotential deposition and carbon monoxide oxidation produced reasonable ECAs on Ir nanoparticles. Capacitance has also previously been used to evaluate the ECAs of Ir and Ir oxide nanoparticles, but would need two different Coulombic charge conversion factors for Ir and Ir oxide (Figure 1). ${ }^{6,10,30,33,39}$ Only mercury underpotential deposition, however, has produced reasonable ECAs for both Ir and Ir oxide, before and following OER characterization, and using the same Coulombic charge conversion factor. Although mercury underpotential deposition on Ir and Ir oxides may occur through different mechanisms, Ir oxidation did not appear to impact the charges due to mercury adsorption and desorption. The ability to evaluate Ir and Ir oxide ECAs permits comparisons of different catalyst types (metals, oxides, surface oxides) and durability studies, since it can decouple surface oxides and their growth from the ECA measurement.

The use of mercury in electrochemical testing presents health and environmental hazards. The National Renewable Energy Laboratory takes specific precautions to limit exposure risks including specific weighing, ventilation, and disposal protocols, and limits to the amount and concentration of mercury used. Due to the associated hazards, mercury is not something we are suggesting for widespread use. Beyond exposure concerns, there are also significant logistical difficulties using mercury measurements in electrolyzer testing. Still, however, we have found a benefit using this technique in performing ex-situ tests and developing novel catalysts. ${ }^{28}$

Table I. Surface areas of Ir and Ir oxide nanoparticles as determined by mercury underpotential deposition, hydrogen underpotential deposition, carbon monoxide oxidation (denoted CO), and BET measurements.

\begin{tabular}{lllll} 
& $\begin{array}{l}\text { Mercury } \\
{\left[\mathrm{m}^{2} \mathrm{~g}_{\mathrm{Ir}}^{-1}\right]}\end{array}$ & $\begin{array}{l}\text { Hydrogen } \\
{\left[\mathrm{m}^{2} \mathrm{~g}_{\mathrm{Ir}}^{-1}\right]}\end{array}$ & $\begin{array}{l}\mathrm{CO} \\
{\left[\mathrm{m}^{2} \mathrm{~g}_{\mathrm{Ir}}{ }^{-1}\right]}\end{array}$ & $\begin{array}{l}\text { BET } \\
{\left[\mathrm{m}^{2} \mathrm{~g}_{\mathrm{Ir}}{ }^{-1}\right]}\end{array}$ \\
\hline Ir & 29.4 & 28.7 & 30.8 & 34 \\
Ir oxide & 28.7 & - & - & 35
\end{tabular}




\section{Conclusions}

Determining Ir ECAs is critical in evaluating OER catalysts and their activities. ECA values allow for the electrochemical baselining of conventional electrolyzer anode catalysts and for comparisons between different catalyst types. These measurements also support durability studies, which can examine catalyst degradation modes and whether losses in activity are due to deteriorating site quantity or quality.

To date, no method commonly used for evaluating Ir ECAs can account for Ir metals, Ir oxides, and produce similar ECAs prior to and following OER characterization using the same Coulombic charge conversion. Hydrogen underpotential deposition can be used to determine the ECAs of Ir metals, but not on oxidized surfaces which form on Ir after operation, and could lead to misinterpreting formed oxides as decreasing site numbers. Carbon monoxide oxidation similarly cannot evaluate oxides and appears to be more sensitive to oxide formation and electrode history, unable to produce ECAs on Ir metals after they have been cycled to high potential. Capacitance can be used to evaluate the ECAs of metals and oxides, but requires two separate conversion factors and cannot decouple oxides and their growth from the ECA measurement. Mercury underpotential deposition was presented in this study as an alternative. This method was previously developed for polycrystalline Ir, and was expanded in this study to include high surface area Ir catalysts, oxides, and OER relevant testing conditions. ${ }^{22,23}$ Data for each method are summarized in Table I. The benefits of mercury adsorption/desorption include the ability to produce surface areas electrochemically that are reasonable and comparable to BET values for Ir and Ir oxide nanoparticles. Mercurybased ECAs also appear immune to cycling at elevated potential, producing surface areas within $5 \%$ of the original value after OER electrochemical conditioning. These types of results and studies are critical to evaluating OER catalysts, and to establishing baselines and testing protocols within electrocatalysis. Having reliable surface area values enables comparative studies on advanced OER electrocatalyst activity and their durability, areas becoming increasing vital within the electrolysis community.

\section{Acknowledgments}

Financial support was provided by the U.S. Department of Energy, SBIR/STTR program under contract \# DE-SC0007471 through Giner, Inc.

\section{References}

1. A. Milbrandt and M. Mann, in, U. S. Department of Energy Editor, http://www.nrel.gov/docs/fy09osti/42773.pdf (2009).

2. J. J. Conti, P. D. Holtberg, J. R. Diefenderfer, S. A. Napolitano, A. M. Schaal, J. T. Turnure, and L. D. Westfall, Annual Energy Outlook 2015, in, U. S. E. I. Administration Editor, U.S. Department of Energy, http://www.eia.gov/forecasts/aeo/pdf/ 0383(2015).pdf (2015).

3. Multi-Year Research, Development, and Demonstration Plan, in, F. C. T. O. Office of Energy Efficiency and Renewable Energy Editor, U.S. Department of Energy, http://energy.gov/sites/prod/files/2015/06/f23/fcto_myrdd_production.pdf (2015).

4. A. Damjanovic, A. Dey, and J. O. M. Bockris, Electrochimica Acta, 11, 791 (1966).

5. W. Sheng, H. A. Gasteiger, and Y. Shao-Horn, Journal of The Electrochemical Soci ety, 157, B1529 (2010).
6. T. Reier, Z. Pawolek, S. Cherevko, M. Bruns, T. Jones, D. Teschner, S. Selve, A. Bergmann, H. N. Nong, R. Schlögl, K. J. J. Mayrhofer, and P. Strasser, Journal of the American Chemical Society, 137, 13031 (2015).

7. H. N. Nong, L. Gan, E. Willinger, D. Teschner, and P. Strasser, Chemical Science, 5, 2955 (2014)

8. H. N. Nong, H. S. Oh, T. Reier, E. Willinger, M. G. Willinger, V. Petkov, D. Teschner, and P. Strasser, Angewandte Chemie International Edition, 54, 2975 (2015).

9. T. Reier, M. Oezaslan, and P. Strasser, ACS Catalysis, 2, 1765 (2012).

10. H.-S. Oh, H. N. Nong, T. Reier, M. Gliech, and P. Strasser, Chemical Science, 6, $3321(2015)$.

11. W. Hu, S. Chen, and Q. Xia, International Journal of Hydrogen Energy, 39, 6967 (2014).

12. W. Hu, Y. Wang, X. Hu, Y. Zhou, and S. Chen, Journal of Materials Chemistry, 22, $6010(2012)$

13. E. A. Paoli, F. Masini, R. Frydendal, D. Deiana, P. Malacrida, T. W. Hansen, I. Chorkendorff, and I. E. Stephens, Catalysis Today, 262, 57 (2016).

14. R. Forgie, G. Bugosh, K. Neyerlin, Z. Liu, and P. Strasser, Electrochemical and Solid-State Letters, 13, B36 (2010).

15. M. Miles, E. Klaus, B. Gunn, J. Locker, W. Serafin, and S. Srinivasan, Electrochimica Acta, 23, 521 (1978)

16. M. Pourbaix, Atlas of electrochemical equilibria in aqueous solutions, National Association of Corrosion Engineers, Houston, Texas (1974).

17. S. M. Alia, S. Pylypenko, K. C. Neyerlin, S. S. Kocha, and B. S. Pivovar, ECS Transactions, 69, 883 (2015)

18. R. Woods, Journal of Electroanalytical Chemistry and Interfacial Electrochemistry, 49, 217 (1974).

19. N. Furuya and S. Koide, Surface Science, 226, 221 (1990).

20. R. Gómez and M. J. Weaver, Langmuir, 14, 2525 (1998).

21. E. Hull, R. Piech, and W. W. Kubiak, Electroanalysis, 20, 2070 (2008).

22. S. P. Kounaves and J. Buffle, Journal of The Electrochemical Society, 133, 2495 (1986).

23. F. Fertonani, E. Milaré, A. V. Benedetti, and M. Ionashiro, Journal of Thermal Analysis and Calorimetry, 67, 403 (2002).

24. S. Kounaves and J. Buffle, Journal of Electroanalytical Chemistry, 239, 113 (1988).

25. S. Zhao, H. Yu, R. Maric, N. Danilovic, C. B. Capuano, K. E. Ayers, and W. E. Mustain, Journal of The Electrochemical Society, 162, F1292 (2015).

26. S. Zhao, H. Yu, R. Maric, N. Danilovic, C. Capuano, K. E. Ayers, and W. E. Mustain, ECS Transactions, 69, 877 (2015).

27. Y. Garsany, O. A. Baturina, K. E. Swider-Lyons, and S. S. Kocha, Analytical Chemistry, 82, 6321 (2010).

28. S. M. Alia, B. Rasimick, C. Ngo, K. C. Neyerlin, S. S. K. S. Pylypenko, H. Xu, and B. S. Pivovar, Activity and Durability of Iridium Nanoparticles in the Oxygen Evolution Reaction, Journal of the Electrochemical Society. Submitted.

29. T. Biegler, D. A. J. Rand, and R. Woods, Journal of Electroanalytical Chemistry and Interfacial Electrochemistry, 29, 269 (1971).

30. C. Rozain, E. Mayousse, N. Guillet, and P. Millet, Applied Catalysis B: Environmental, 182, 153 (2016).

31. S. Ardizzone, G. Fregonara, and S. Trasatti, Electrochimica Acta, 35, 263 (1990).

32. G. Lodi, E. Sivieri, A. Battisti, and S. Trasatti, Journal of Applied Electrochemistry, 8, 135.

33. E. Rasten, G. Hagen, and R. Tunold, Electrochimica Acta, 48, 3945 (2003).

34. B. Aurian-Blajeni, X. Beebe, R. D. Rauh, and T. L. Rose, Electrochimica Acta, 34, 795 (1989).

35. J. D. Weiland, D. J. Anderson, and M. S. Humayun, Biomedical Engineering, IEEE Transactions on, 49, 1574 (2002).

36. S. F. Cogan, P. R. Troyk, J. Ehrlich, T. D. Plante, and D. E. Detlefsen, Biomedical Engineering, IEEE Transactions on, 53, 327 (2006).

37. L. S. Robblee, M. J. Mangaudis, E. D. Lasinsky, A. G. Kimball, and S. B. Brummer, in MRS Proceedings, p. 303 (1985).

38. S. F. Cogan, Annu. Rev. Biomed. Eng., 10, 275 (2008)

39. C. C. L. McCrory, S. Jung, I. M. Ferrer, S. M. Chatman, J. C. Peters, and T. F. Jaramillo, Journal of the American Chemical Society, 137, 4347 (2015).

40. H. A. Gasteiger, N. Markovic, P. N. Ross, and E. J. Cairns, The Journal of Physical Chemistry, 98, 617 (1994).

41. K. J. J. Mayrhofer, D. Strmcnik, B. B. Blizanac, V. Stamenkovic, M. Arenz, and N. M. Markovic, Electrochimica Acta, 53, 3181 (2008).

42. G. J. Edens, A. Hamelin, and M. J. Weaver, The Journal of Physical Chemistry, 100, 2322 (1996).

43. K. Kunimatsu, The Journal of Physical Chemistry, 88, 2195 (1984).

44. Y. Bonfil, M. Brand, and E. Kirowa-Eisner, Analytica chimica acta, 424, 65 (2000). 